\title{
Genetic admixture analysis in Prestice Black-Pied pigs
}

\author{
I. Vrtková \\ Laboratory of Agrogenomics, Mendel University in Brno, Brno, Czech Republic \\ Correspondence to: I. Vrtková (irenav@ mendelu.cz)
}

Received: 22 May 2014 - Accepted: 12 January 2015 - Published: 23 March 2015

\begin{abstract}
The Prestice Black-Pied pig (PC) is a genetic resource of the Czech Republic. Information about boar variability has been provided in preceding papers. The objective of this work was to compare genetic variability of boars and sows. A total of 21 microsatellite markers were used to study genetic diversity and population structure of 149 PC breeding animals. In this paper, current parameters of assessments of diversity in PC are listed. All loci were polymorphic, and a total of 167 alleles were observed across the studied loci. The range of alleles was found to be 4 to 15 with a mean of 7.95 . Overall allele frequency ranged from 0.07 to 0.25 . The calculated observed and expected heterozygosity values were 0.70 and 0.73 , respectively. The polymorphism information content (PIC) was 0.69 and the overall within-population inbreeding estimate $\left(F_{\text {IS }}\right)$ was 0.04 . Genetic differentiation and population subdivision were tested. The level of admixture of breeds used for improvement of the PC breed was evaluated (Landrace, Large White and Pietrain). Five percent of analysed PC breeding boars had more than $20 \%$ admixture of other monitored breeds. The obtained results are important for the future sustainability of this local breed.
\end{abstract}

\section{Introduction}

Knowledge of molecular structure helps in achieving sustainability of genetic resources. First of all, microsatellite markers are used. The main characteristics of the substantial part of European local pig breeds were summarized by SanCristobal et al. (2006).

The most detailed information is available about the Spanish Iberian pig breed (Martínez et al., 2000; Toro et al., 2002; Fabuel et al., 2004; Alves et al., 2006; Rodrigáñez et al., 2008; Herrero-Medrano et al., 2013). All authors used data on microsatellite markers in order to describe the genetic variability of Iberian pigs.

Because of comparison with our results, we cite the paper of Guastella et al. (2010), who described parameters of diversity obtained by using microsatellites of the Italian Nero Siciliano pig breed. In his work, Ollivier (2009) summarized genetic diversity within and between European pigs.

The papers published by Wang et al. (2011), BerthoulySalazar et al. (2012), Chen et al. (2012) and Zaman et al. (2013) contributed to the expansion of knowledge of isolated local breeds in Asia.
The first information about microsatellite analysis of the Czech local breed Prestice Black-Pied pig (PC) comes from the PigBioDiv project. In a study about heterozygosity, Megens et al. (2008) reported heterozygosity (Ho) of 0.69 for PC. In other published local and commercial breeds, Ho ranged from 0.51 (Italian Mora Romagnola breed) to 0.74 (Chinese Tibetan/Zang breed).

The PC pig breed has the shortest distance to Angler Sattelschwein in two compiled dendrograms of local breeds (OIlivier, 2007). The French Créole breed and Italian Nero Siciliano breed were assigned to the same branch.

In the second available dendrogram constructed by Megens et al. (2008), 98 lines and pig breeds are represented. Nero Siciliano is the nearest breed to PC. Angler Sattelschwein is closer to the Polish Pulawska breed in this dendrogram, while the French Créole breed is closer to the breeds British Large Black and British Saddleback.

The progress of the PC pig varied according to opinions about its improvement and efforts of traditional breeders aimed at its conservation.

In 1964, PC was officially recognized as a particular breed. The breed was recognized as a genetic resource in 1992. 
Since 1996, it has been kept in line with the instructions for genetic resources with controlled breeding work.

During preparations for the declaration of $\mathrm{PC}$ as a genetic resource, the technology for detection of microsatellites had come into use globally; however, the technology was not taken into account for PC.

For the first time, after more than 15 years since recognizing PC as a genetic resource, variability in microsatellites was identified, and diversity was evaluated by Vrtková et al. (2013) using contemporary software. The authors provide information on only the variability of boars that were included in reproduction in 2002-2011 in all herds of PC pigs in the Czech Republic.

The objective of this study was to include breeding sows of PC in the analysed set and to assess differences between males and females. In breeding boars a possibility of evaluating the share of breeds used for the improvement of PC pig was tested.

\section{Material and methods}

\subsection{Samples}

For the analysis of PC pigs, a total of 149 pigs (89 PC breeding boars and 60 PC breeding sows) were used. These pigs, registered in a herd book of genetic resources, were analysed via the typing of 21 microsatellites.

To evaluate admixtures of other pig breeds in a total of 400 breeding boars from three commercial breeds, Pietrain (PN), Large White (LW), Landrace (LA) and genetic resource PC were sampled, i.e. 100 pigs from each breed, and analysed for 10 microsatellite markers.

DNA for analysis was isolated from blood or hair samples.

\subsection{Microsatellite, PCR amplification}

A total of 21 microsatellite markers were used for the analysis of PC pigs. For comparison with other breeds, a panel of 10 microsatellite markers was used that is applied in the $\mathrm{CZ}$ for origin testing, and therefore a sufficient number of tested pigs was available.

Polymerase chain reaction (PCR) was carried out in two multiplex reactions. Nine dinucleotide markers - S0068, S0107, SW24, S0355, S0386, SW353, SW936, S0070, SW72, out of which S0355, S0068, SW24, SW936 and SW72 are recommended by ISAG-FAO for diversity studies in pigs (FAO, 2011) - and one trinucleotide marker, TNFB, were analysed in one multiplex reaction.

The second multiplex reaction contained 11 tetranucleotide markers - 387A12F, S0655, SBH1, SBH2, SBH4, SBH10, SBH13, SBH18, SBH19, SBH20 and SBH22 - included in an Animaltype Pig kit (Biotype Diagnostic GmbH). The Animaltype Pig kit is a PCR test specifically developed for the genotyping of breeding livestock samples for the proof of origin in meat products and generally for qual- ity management in the food industry. The test kit is recommended for the following applications: proof of origin according to the EU directive, kinship testing in the context of control of breeding, and status of inbreeding for herd book populations.

Microsatellite markers were separated by fragment analysis on an ABI PRISM 310 genetic analyser (Applied Biosystems, Foster City, USA). Fragment analysis was carried out using GeneScan 3.7 and Genotyper 3.7 software.

\subsection{Statistical analysis}

The allele frequency, the number of alleles per locus $(\mathrm{Na})$, the mean number of alleles per locus (MNA), polymorphism information content (PIC), observed heterozygosity (Ho) and expected heterozygosity $(\mathrm{He})$ were obtained across different loci using the Excel Microsatellite Toolkit v. 3.1.1. (Park, $2001)$. Fixation coefficients $\left(F_{\mathrm{IS}}, F_{\mathrm{ST}}\right)$ were calculated according to Weir and Cockerham (1984) using Genepop v. 4.1. (Rousset, 2007).

Genetic differentiation and population subdivision were tested using the algorithm of Pritchard et al. (2000) implemented in Structure v. 2.2 software. Individual animals were assigned to two or more subpopulations on the basis of their microsatellite genotypes. The Structure software is able to determine, for each pig, the proportion of genes originating from the " $K$ " potential clusters. The Structure algorithm based on the Markov chain Monte Carlo method (MCMC) was used to define the natural algorithm of the probability that a given genotype belongs to the assumed $K$ clusters. The run length was set to the burn-in period of $10^{5}$ interactions followed by $10^{5}$ interactions suggested by Pritchard et al. (2000). The program was tested in the range of possible clusters $(K)$ from 2 to 5 .

\section{Results}

\subsection{Genetic structure in Prestice Black-Pied breed}

\section{Genetic variability at microsatellite loci}

Genetic variability at microsatellite loci in PC pigs, such as allele number, allele size, polymorphic information content (PIC) and intrapopulation fixation index $\left(F_{\mathrm{IS}}\right)$, is listed in Table 1 .

The number of alleles in a microsatellite ranged from 4 (SBH19) to 15 (S0070). Alleles with a frequency lower than 0.005 were detected at loci S0655, SBH2, SBH10, SBH18, SBH20, S0068, SW24, S0386 and S070.

Exclusive alleles for the PC breed were found at loci 387A12F, SBH4 and SBH10 compared to the population study performed by Biotype Diagnostic $\mathrm{GmbH}$ on variability of tetranucleotide microsatellites in LW, LA and PN breeds kept in Germany.

The value of observed heterozygosity ranged from 0.39 for marker SW355 to 0.90 for marker S0070. The loci SBH18 
and S0355 showed much lower observed heterozygosity than expected.

The present genetic variability in the PC breed and a comparison between males and females are documented in Table 2 . The total number of 167 alleles was identified for the 21 microsatellite loci in PC. The total mean number of alleles per locus was 7.95, with a standard deviation (SD) of 2.91. The average observed heterozygosity for the population was 0.70 (SD 0.01). $F_{\text {IS }}$ for the PC population was 0.04 . In strict selection of boars into selective breeding, we had 89 breeding boars. Sixty head of breeding stock from selected pedigree sows were available.

The number of alleles per locus in boars ranged from 4 (SBH19, SW353) to 12 (SBH2, S070), and in sows from 3 (SBH19, S0355) to 11 (SBH2). The total number of alleles was higher in boars. Overall allele frequency in boars was from 0.08 (SBH2, S070) to 0.25 (SBH19, SW353), and in sows from 0.09 (SBH2) to 0.33 (SBH19, S0355). At least one allele with a frequency higher than 0.5 was identified in boars for markers SBH13, SBH19, SBH20 SBH22, S0355, S0386 and SW353. In sows, at least one allele with a frequency higher than 0.5 was revealed for markers SBH13, SBH19, SBH20, S0107, S0386 and SW353. The differences between boars and sows in this parameter are in markers SBH22, S0355 and S0107.

The lowest observed heterozygosity in boars was determined for loci SHB18 and S0355 (0.41 and 0.49, respectively); for sows the lowest was for S0355 and SW353 (0.25 and 0.20 , respectively). For all other loci in both subpopulations, heterozygosity higher than 0.5 was observed. Average observed heterozygosity was 0.71 in boars and 0.68 in sows. Average PIC for 21 loci was 0.68 in boars and 0.37 in sows. $F_{\text {IS }}$ in boars was twice as high as sows' $F_{\text {IS }}: 0.03$ and 0.01 , respectively.

The $F_{\mathrm{ST}}$ coefficient between boars and sows was 0.04 , which may be interpreted that structuring between them is weak.

Despite the low value of $F_{\mathrm{ST}}$, a clustering method shows two different clusters when the common population of boars and sows was clustered. With $K=2$, sows were identified as an independent cluster (see Fig. 1).

\subsection{Analysis of breeding boars}

Breeding boars are considered to be the main factor affecting breed sustainability. The effect of single loci at the breeding of PC boars is shown in Table 3.

Negative $F_{\text {IS }}$ values were observed for 12 markers out of the 21 analysed ones (387A12F, S0655, SBH1, SBH10, SBH13, SBH19, SBH20, S0068, S0386, S070, SW72, TNFB). These negative values indicate the excess of heterozygotes. Higher $F_{\text {IS }}$ values were found for markers S0355 (0.21), SBH18 (0.50) and SW353 (0.12).
Table 1. Summary statistics for 21 microsatellite loci analysed in Prestice Black Pied pig.

\begin{tabular}{|c|c|c|c|c|}
\hline Loci & $\mathrm{Na}$ & Allele size & PIC & $F_{\text {IS }}$ \\
\hline $387 \mathrm{~A} 12 \mathrm{~F}$ & 8 & $\begin{array}{l}9,12.1,13,14.1,15 \\
18,21, \mathbf{2 2}\end{array}$ & 0.73 & -0.07 \\
\hline S0655 & 6 & $5,9,10,11,12,13$ & 0.58 & 0.01 \\
\hline SBH1 & 6 & $10,12,13,14,15,16$ & 0.71 & -0.03 \\
\hline $\mathrm{SBH} 2$ & 12 & $\begin{array}{l}6,21,23,25,26,27 \\
28,30,31,32,33 \\
34\end{array}$ & 0.76 & 0.03 \\
\hline SBH4 & 11 & $\begin{array}{l}55.1,56,57,58,59, \\
60,62, \mathbf{6 3}, 64,65.1, \\
66.1\end{array}$ & 0.84 & 0.08 \\
\hline SBH10 & 10 & $\begin{array}{l}34,36,37,40,41 \\
42,46,48,49, \mathbf{5 3}\end{array}$ & 0.82 & 0.02 \\
\hline SBH13 & 6 & $9,11,13,14,15,16$ & 0.54 & -0.05 \\
\hline SBH18 & 10 & $\begin{array}{l}11,13,14,15,16 \\
17,19,22,23,24\end{array}$ & 0.82 & 0.30 \\
\hline SBH19 & 4 & $10,11,14,15$ & 0.53 & -0.01 \\
\hline $\mathrm{SBH} 20$ & 9 & $\begin{array}{l}26,31,32,34,37 \\
38,39,40,42\end{array}$ & 0.62 & -0.01 \\
\hline SBH22 & 5 & $18,19,20,23.3,24$ & 0.55 & 0.05 \\
\hline S0068 & 12 & $\begin{array}{l}217,225,231,237 \\
241,243,245,247 \\
249,251,255,257\end{array}$ & 0.74 & 0.03 \\
\hline S0107 & 8 & $\begin{array}{l}166,174,176,178, \\
194,196,198,220\end{array}$ & 0.69 & 0.01 \\
\hline SW24 & 9 & $\begin{array}{l}93,95,99,101,105 \\
107,109,113,117\end{array}$ & 0.73 & 0.02 \\
\hline S0355 & 5 & $\begin{array}{l}241,245,255,259, \\
263\end{array}$ & 0.56 & 0.38 \\
\hline S0386 & 5 & $\begin{array}{l}164,172,174,180, \\
182\end{array}$ & 0.55 & -0.08 \\
\hline SW353 & 5 & $\begin{array}{l}138,140,144,148, \\
150\end{array}$ & 0.51 & 0.28 \\
\hline SW936 & 7 & $\begin{array}{l}89,91,93,101,105 \\
107,109\end{array}$ & 0.68 & -0.03 \\
\hline S0070 & 15 & $\begin{array}{l}260,262,264,266, \\
270,272,274,276, \\
278,280,282,286, \\
288,292,294\end{array}$ & 0.89 & -0.01 \\
\hline SW72 & 6 & $\begin{array}{l}97,99,105,107,109, \\
113\end{array}$ & 0.71 & -0.08 \\
\hline TNFB & 8 & $\begin{array}{l}156,159,162,168 \\
171,180,183,186\end{array}$ & 0.85 & 0.05 \\
\hline
\end{tabular}

Na: number of alleles observed; Allele size: observed in PC breed, with those shown in bold being alleles exclusive for the PC breed compared to the Biotype Diagnostic GmbH population study; PIC: polymorphism information content; $F_{\text {IS }}$ : intrapopulation fixation index.

\subsection{Development of heterozygosity of breeding boars over 10 years}

In our study, we have estimated variability in a group of breeding boars that were included in reproduction in 20022011. Eighty-nine boars were used in reproduction during those 10 years. The mean number of alleles per locus was 
Table 2. Microsatellite diversity in PC breed and comparison between sex.

\begin{tabular}{lrrrrrrrrrr}
\hline & $n$ & TNA & MNA & MNA SD & He & He SD & Ho & Ho SD & PIC & $F_{\text {IS }}$ \\
\hline PC population & 149 & 167 & 7.95 & 2.91 & 0.73 & 0.02 & 0.70 & 0.01 & 0.69 & 0.04 \\
Boars & 89 & 156 & 7.43 & 2.46 & 0.73 & 0.02 & 0.71 & 0.01 & 0.68 & 0.03 \\
Sows & 60 & 127 & 6.05 & 1.96 & 0.69 & 0.02 & 0.68 & 0.01 & 0.37 & 0.01 \\
\hline
\end{tabular}

$n$ : number of analysed samples; TNA: total number of alleles observed; MNA: mean number of alleles per locus; Ho: observed heterozygosity; He: expected heterozygosity; PIC: polymorphism information content; $F_{\text {IS }}$ : intrapopulation fixation index; SD: standard deviation.

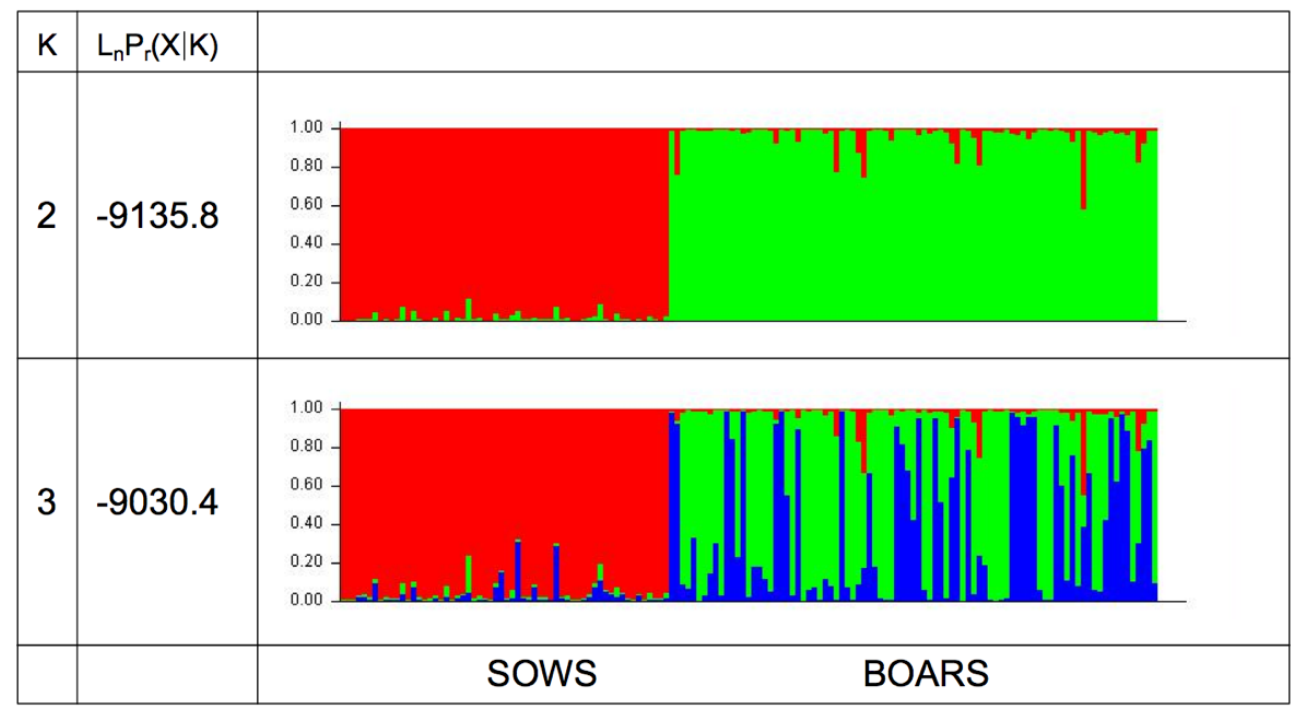

Figure 1. Graphical representation of the estimated membership fractions of individuals of the sows and boars analysed in each of the $K$ inferred clusters, for $K=2$ to $K=3$.

from 3.90 (2002) to 5.62 (2005). In the last reference year, 2011, this number was 4.00. Observed heterozygosity was highest in 2005 (0.76), and lowest in 2010 (0.59). In 6 years, expected heterozygosity was higher than observed heterozygosity.

The values of observed heterozygosity of boars included in reproduction in 2002-2011 are shown in Fig. 2.

\subsection{Assigning PC boars to breed origin by clustering method}

We focused on the evaluation of three breeds - LA, LW and $\mathrm{PN}$ - which were involved in the improvement of the PC breed according to our information. The number of clusters was from $K=2$ to $K=5$. For $K=2 \mathrm{LA}$, LW (green) and $\mathrm{PC}$ and $\mathrm{PN}$ (red) were distinguished. For $K=3, \mathrm{PC}$ and PN (blue) were included in the same cluster. For $K=4$, PC was characterized as an independent population (yellow) (see Fig. 3).

When we look at the cluster of the PC population, we can see shares of other breeds. The cluster is shown in Fig. 4.

A more detailed analysis of clustering of PC boars provided these results: three of them contain a higher share of

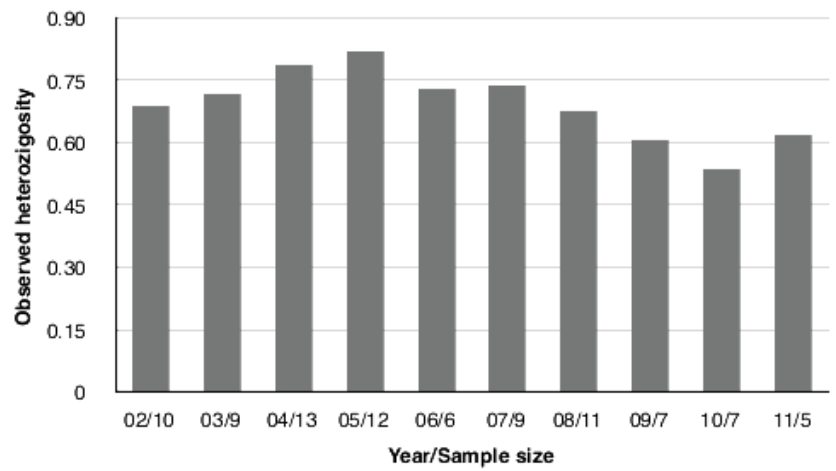

Figure 2. Development of observed heterozygosity in breeding PC boars during 2002-2011.

other monitored breeds - one boar $39 \%$ of LW, one boar $50 \%$ of PN, and one boar $29 \%$ of PN and $23 \%$ of LA. All other PC boars contain smaller shares of monitored breeds, mainly PN and LA. This is consistent with the breeding of $\mathrm{PC}$ pigs in the last years.

When the number of clusters assumed was the same as the number of breeds $(K=4)$, the PC breed was very closely 
Table 3. Microsatellite diversity in breeding PC boars.

\begin{tabular}{llrrrr}
\hline Loci & $\mathrm{Na}$ & $\mathrm{He}$ & Ho & PIC & $F_{\text {IS }}$ \\
\hline 387A12F & 8 & 0.78 & 0.81 & 0.75 & -0.04 \\
S0655 & 6 & 0.68 & 0.70 & 0.63 & -0.03 \\
SBH1 & 6 & 0.76 & 0.82 & 0.72 & -0.08 \\
SBH2 & 12 & 0.80 & 0.77 & 0.77 & 0.03 \\
SBH4 & 10 & 0.87 & 0.83 & 0.85 & 0.05 \\
SBH10 & 9 & 0.81 & 0.81 & 0.77 & -0.01 \\
SBH13 & 6 & 0.60 & 0.63 & 0.55 & -0.07 \\
SBH18 & 9 & 0.81 & 0.41 & 0.78 & 0.50 \\
SBH19 & 4 & 0.61 & 0.64 & 0.54 & -0.04 \\
SBH20 & 8 & 0.67 & 0.69 & 0.63 & -0.02 \\
SBH22 & 5 & 0.58 & 0.55 & 0.52 & 0.01 \\
S0068 & 11 & 0.77 & 0.78 & 0.73 & -0.01 \\
S0107 & 8 & 0.76 & 0.74 & 0.73 & 0.03 \\
SW24 & 9 & 0.78 & 0.73 & 0.75 & 0.06 \\
S0355 & 5 & 0.61 & 0.49 & 0.55 & 0.21 \\
S0386 & 5 & 0.64 & 0.68 & 0.57 & -0.07 \\
SW353 & 4 & 0.60 & 0.53 & 0.55 & 0.12 \\
SW936 & 7 & 0.76 & 0.72 & 0.71 & 0.05 \\
S0070 & 12 & 0.83 & 0.91 & 0.80 & -0.10 \\
SW72 & 6 & 0.75 & 0.76 & 0.71 & -0.02 \\
TNFB & 6 & 0.80 & 0.84 & 0.76 & -0.06 \\
\hline
\end{tabular}

$\mathrm{Na}$ : total number of alleles observed; Ho: observed heterozygosity; He: expected heterozygosity; PIC: polymorphism information content; $F_{\mathrm{IS}}=$ intrapopulation fixation index.

associated with one of the ancestral populations from which it received a contribution to its gene pool. The respective results are summarized in Table 4.

\section{Discussion}

Development of genetic resources of $\mathrm{PC}$ has resulted from both unregulated breeding with Old Czech Bristled pigs and crossbreeding with boars of different breeds from Germany and England. In 1952, Wessex Saddleback pig was used. PC was crossbred with Pietrain in 1966, with Welsh in 1985 and with Landrace in 1986.

Genetic variations and heterozygosity were estimated and assignment tests were performed within and between sets of PC breeding boars and breeds used for its improvement (PN, LA, LW). The results of this study confirm that the local breed of PC pig represents a very interesting reservoir of allelic diversity and that there was a small admixture between the four studied breeds.

Martínez et al. (2012) believe that the knowledge of the structure of a livestock population in terms of sources of variability between and within breeds is the most crucial. It is essential for defining conservation priorities and strategies, with the long-term objective of maintaining genetic diversity for future generations. Our information about PC has been the first so far; therefore we consider it to be a substantial contribution in accord with the cited author.
Table 4. Proportional contribution of the PC cluster.

\begin{tabular}{l|lllll}
\hline Breed & \multicolumn{5}{|c}{ Proportional contribution of the PC cluster } \\
\hline PC & $0.95-1.00$ & $0.90-0.95$ & $0.85-0.90$ & $0.80-0.85$ & $0.75-0.80$ \\
$n$ & 57 & 27 & 8 & 3 & 2 \\
\hline
\end{tabular}

$n=$ number of boars.

Based on divergence in dendrograms in Ollivier (2007) and Megens et al. (2008), we can compare heterozygosity in four microsatellite markers in Nero Siciliano. Guastella et al. (2010) analysed four microsatellite markers that were identical to our (S0355, SW936, SW72 and SW24). Parameters of diversity in the given markers for Nero Siciliano vs. PC are as follows: locus S0355 - Na 8/5, Ho 0.43/0.39, $F_{\text {IS }} 0.12 / 0.38$; locus SW936 - Na 11/7, Ho 0.68/0.75, $F_{\text {IS }} 0.09 /-0.03$; locus SW72 - Na 9/6, Ho 0.73/0.81, $F_{\text {IS }} 0.03 /-0.08$; and locus SW24 - Na 11/9, Ho 0.78/0.75, $F_{\text {IS }} 0.05 / 0.02$.

The total $\mathrm{Ho}=0.70$ of the PC breed is considered as sufficient for the monitored population.

For the sustainability of gene resources, efforts are being made to increase the number of lines in boar selection. The lowest possible relatedness of particular boars is observed, which may be one of the major causes of higher variability in boars reflected mainly in the number of present alleles (see Table 2)

A comparison of heterozygosity of boars and sows showed higher heterozygosity of boars, which is consistent with the allele number.

Because we consider it important in boars, their heterozygosity in the last decade was evaluated (Fig. 2). In the particular years, the boars that were included in reproduction in a given year were evaluated. Different values of heterozygosity may reflect the engagement of the various lines of boars. The gradual decline of Ho to the lowest value in 2010 highlights the need for taking this parameter into consideration in the selection of PC boars. Genotypes with alleles of low frequency should be preferred and genotypes with an allele frequency higher than 0.5 should be reduced. The samples of all analysed sows were obtained within 1 year, which did not allow for the same analysis to be performed as for boars.

Clustering methods are different according to the routing information capability. Using modified clustering methods, Wilkinson et al. (2011) divided the initially declared single-breed British Saddleback into two separate populations. Due to different variants of selection and admixture of other breeds, there was a similar option between sows and boars within the PC. The basic clustering method used by us indicates this opportunity (Fig. 1).

Our goal was to identify breeding boars with higher admixture of other breeds and use this knowledge in breeding work with the local breed PC. If only three boars contained a larger proportion of other studied breeds (one PC boar contained $29 \%$ of LW, one PC boar contained $50 \%$ of PN, and 


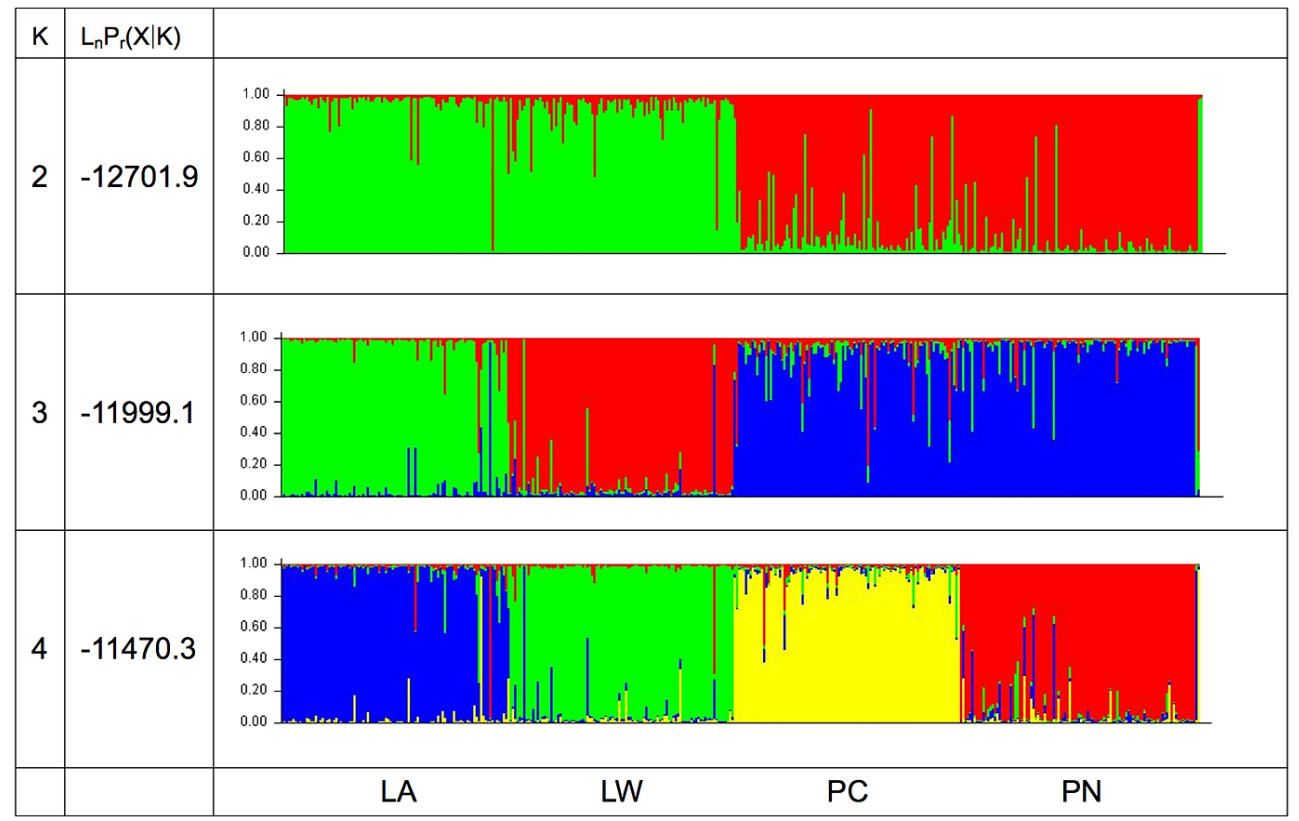

Figure 3. Graphical representation of the estimated membership fractions of individuals of the breed analysed in each of the $K$ inferred clusters, for $K=2$ to $K=4$.
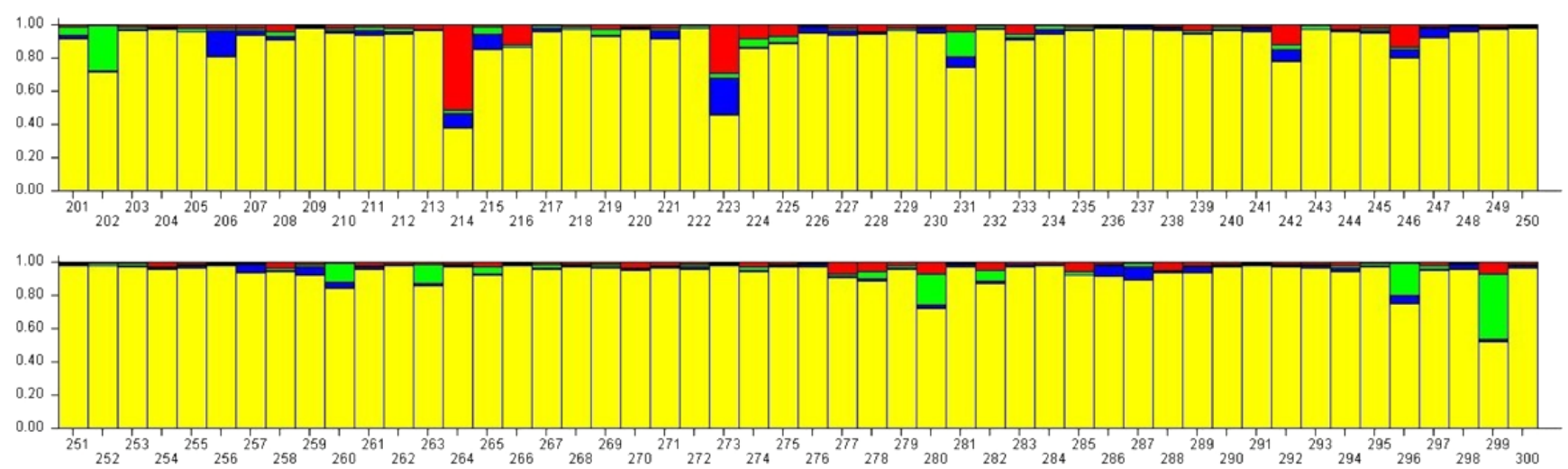

Figure 4. Cluster of PC boars by individual.

one PC boar contained $25 \%$ of LW and $23 \%$ of LA), i.e. $3 \%$, it is advisable to restrict their use. Gradually, we can create a more uniform population of PC breed pigs.

Because, even on small pig farms, the rearing of PC breed pigs is beginning to expand to the production of pork, the method could also be used with a certain probability to determine the origin of meat declared as meat from PC animals.

Acknowledgements. This work was supported through project no. QJ1210253 of the Ministry of Agriculture of the Czech Republic.

Edited by: K. Wimmers

Reviewed by: two anonymous referees

\section{References}

Alves, E., Fernández, A., Barragán, C., Ovilo, C., Rodríguez, C., and Silió, L.: Inference of hidden population substructure of the Iberian pig breed using multilocus microsatellite data, Span. J. Agric. Res., 4, 37-46, 2006.

Berthouly-Salazar, C., Thévenon, S., Nhu Van, T., Nguyen, B. T., Pham, L. D., Vu Chi, C., and Maillard, J. C.: Uncontrolled admixture and loss of genetic diversity in a local Vietnamese pig breed, Ecol. Evol., 2, 962-975, 2012.

Chen, Y. C., Hsu, J. T., Chen, C. C., Leu, Y. C., Chyr, C. Y. L., Lin, D. Y., Lin, E. C., Chen, C. H., and Wang, P. H.: Investigation of Genetic Relationships Among Taiwan Black Pigs and Other Pig Breeds in Taiwan Based on Microsatellite Markers, Anim. Biotechnol., 23, 278-290, 2012. 
Fabuel, E., Barragán, C., Silió, L., Rodríguez, M. C., and Toro, M. A.: Analysis of genetic diversity and conservation priorities in Iberian pigs based on microsatellite markers, Heredity, 93, 104113, 2004.

FAO: Molecular genetic characterization of animal genetic resources. FAO Animal Production and Health Guidelines, No.9. Rome, Italy, available at: http://www.fao.org/docrep/014/i2413e/ i2413e00.pdf (last access: February 2015), 2011.

Guastella, A. M., Criscione, A., Marletta, D., Zuccaro, A., Chies, L., and Bordonaro, S.: Molecular characterization and genetic structure of the Nero Siciliano pig breed, Genet. Mol. Biol., 33, 650-656, 2010.

Herrero-Medrano, J. M., Megens, H. J., Crooijmans, R. P., Abellaneda, J. M., and Ramis, G.: Farm-by-farm analysis of microsatellite, mtDNA and SNP genotype data reveals inbreeding and crossbreeding as threats to the survival of a native Spanish pig breed, Anim. Genet., 44, 259-266, 2013.

Martínez, A. M., Delgado, J. V., Rodero, A., and Vega-Pla, J. L.: Genetic structure of the Iberian pig breed using microsatellites, Anim. Genet., 31, 295-301, 2000.

Martínez, M. A., Landi Periati, V., Martínez Domínguez, M., Poto Remacha, A., Peinado Ramon, B., Gómez, M., Pons, A., Barba Capote, C., Carril González-Barros, J. A., Méndez Tur, Y., VegaPla, J. L., and Delgado, J. V.: Genetic characterization of autochthonous pig breeds from Spain with microsatellite markers, in: Proceedings of the 7th International Symposium on the Mediterranean Pig, edited by: De Pedro, E. J. and Cabezas, A. B., 14-16 October 2010, Córdoba, Spain (Options méditerranéennes, Series A: Mediterranean Seminars, No. 101), CIHEAM, Zaragoza, Spain, 31-37, 2012.

Megens, H. J., Crooijmans, R. P. M. A., San Cristobal, M., Hui, X., Li, N., and Groenen, M. A. M.: Biodiversity of pig breeds from China and Europe estimated from pooled DNA samples: differences in microsatellite variation between two areas of domestication, Genet. Sel. Evol., 40, 103-128, 2008.

Ollivier, L.: Analyses of the European Pig diversity using genetic markers, in: Proceedings of the 6th international Symposium on the Mediterranean Pig, edited by: Nanni Costa, L., Zambonelli, P., and Russo, V., Messina, Italy, 11-13 October 2007, 10-22, 2007.

Ollivier, L.: European pig genetic diversity: a minireview, Animal, 3, 915-924, 2009.
Park, S. D. E.: Trypanotolerance in West African Cattle and the Population Genetic Effects of Selection, $\mathrm{PhD}$ thesis, University of Dublin, Dublin, Republic of Ireland, 2001.

Pritchard, J. K., Stephens, M., and Donnelly, P.: Inference of Population Structure Using Multilocus Genotype Data, Genetics, 155, 945-959, 2000.

Rodrigáñez, J., Barragán, C., Alves, E., Gortázar, C., Toro, M. A., and Silió, L.: Genetic diversity and allelic richness in Spanish wild and domestic pig population estimated from microsatellite markers, Span. J. Agric. Res., 6, 107-115, 2008.

Rousset, F.: Genepop'007: a complete re-implementation of the GENEPOP software for Windows and Linux, Mol. Ecol. Resour., 8, 103-106, 2007.

SanCristobal, M., Chevalet, C., Haley, C. S., Joosten, R., Rattink, A. P., Harlizius, B., Groenen, M. A. M., Amigues, Y., Boscher, M. Y., Russell, G., Law, A., Davoli, R., Russo, V., Désautés, C., Alderson, L., Fimland, E., Bagga, M., Delgado, J. V., Vega-Pla J. L., Martinez, A. M., Ramos, M., Glodek, P., Meyer, J. N., Gandini, G. C., Matassino, D., Plastow, G. S., Siggens, K. W., Laval, G., Archibald, A. L., Milan, D., Hammond, K., and Cardellino, R.: Genetic diversity within and between European pig breeds using microsatellite markers, Anim. Genet., 37, 189-198, 2006.

Toro, M., Barragán, C., Óvilo, C., Rodrigáñez, J., Rodriguez, C., and Silió, L.: Estimation of coancestry in Iberian pigs using molecular markers, Conserv. Genet., 3, 309-320, 2002.

Vrtková, I., Stehlík, L., and Putnová, L.: Research of variability in Prestice Black Pied pig using dinucleotide and tetranucleotide microsatellite markers, Research in Pig Breeding, 7, 9-14, 2013.

Wang, J. Y., Guo, J. F., Zhang, Q., Hu, H. M., Lin, H. C., Wang, C., Zhang, Y., and Wu, Y.: Genetic Diversity of Chinese Indigenous Pig Breeds in Shandong Province Using Microsatellite Markers, Asian-Aust, J. Anim. Sci., 24, 28-36, 2011.

Weir, B. S. and Cockerham, C. C.: Estimating F-Statistics for the Analysis of Population Structure, Evolution, 38, 1358-1370, 1984.

Wilkinson, S., Haley, C., Alderson, L., and Wiener, P.: An empirical assessment of individual-based population genetic statistical techniques: application to British pig breeds, Heredity, 106, 261269, 2011.

Zaman, G., Chandra Shekar, M., and Aziz, A.: Molecular Characterization of Meghalaya Local Pigs (Niang Megha) using Microsatellite Markers, Indian J. Sci. Technol., 6, 5302-5306, 2013. 